\title{
Profile of Self Help Groups (SHGs) and their Members Engaged in Pig Rearing Activity in Mizoram
}

\author{
Hmingthanzuala ${ }^{1}$, Samares Kumar Das ${ }^{1 *}$, Saidur Rahman ${ }^{1}$, T. C. Tolenkhomba ${ }^{2}$ and Prasanta Saikia ${ }^{3}$ \\ ${ }^{1}$ Dept. of Veterinary \& Animal Husbandry Extension, College of Veterinary Sciences \& Animal Husbandry, \\ Central Agricultural University, Selesih, Aizawl, Mizoram (796 014), India \\ ${ }^{2}$ Dept. of Animal Genetics and Breeding, College of Veterinary Sciences \& Animal Husbandry, \\ Central Agricultural University, Selesih, Aizawl, Mizoram (796 014), India \\ ${ }^{3}$ Dept. of Livestock Production Management, College of Veterinary Sciences \& Animal Husbandry, \\ Central Agricultural University, Selesih, Aizawl, Mizoram (796 014), India
}

\section{Article History}

Manuscript No. AR1660

Received in $16^{\text {th }}$ June, 2016

Received in revised form $30^{\text {th }}$ September, 2016

Accepted in final form $6^{\text {th }}$ October, 2016

\section{Correspondence to}

*E-mail: samcau.d1@gmail.com

\section{Keywords}

Mizoram, SHGs, pig rearing, profile of SHGs.

\begin{abstract}
Self Help Groups (SHGs) have shown the way for the poor. Impressed by the success of women SHGs in Andhra Pradesh, the World Bank recommended replicating the model in other states in India. In Mizoram, the strength of SHGs is ever growing with the initiative taken by government agencies such as National Bank for Agriculture and Rural Development (NABARD), District Rural Development Agency (DRDA), etc. However, there is a dearth of studies on SHGs in Mizoram. Present study was undertaken in the district of Serchhip and Kolasib of Mizoram where the National Rural Livelihood Mission (NRLM) had been forming SHGs around piggery since 2012. The objective was to study the socio-economic profile of SHGs and their members. Profile of SHGs included age, members and their type, group activities (savings, internal lending, group meeting, election, and training). Profile of members included age, education, occupation, income, family size, land holding, experience in piggery, and herd size. The study concludes that SHG can be promoted among young and old. Members were literate which was an advantage. Pig rearing as a SHG activity was compatible to the society. Members joined to form Joint Liability Group (JLG). There was a scope for the government agencies to involve in the formation of SHGs. There is a need to study the relationship between profile of SHGs and their members, and the sustainability of SHGs.
\end{abstract}

\section{Introduction}

There are several problems that can be better solved through group efforts. These groups have been known as Self Help Groups (SHGs). SHGs have shown the way for the poor and marginalized. Impressed by the remarkable success of women SHGs in Andhra Pradesh, the World Bank recommended that the model could be replicated in other states in India and in other countries (Ramesh, 2007; Reddy, 2008). In the context of developing programs for the poor, SHGs have emerged as effective tools for poverty alleviation as well as for social and economic empowerment of the rural poor, particularly women (Kashid et al., 2009; Sajesh et al., 2011). In Mizoram, the strength of SHG is growing with the initiative taken by government agencies such as National Bank for Agriculture and Rural Development (NABARD), District Rural Development Agency (DRDA), Mizoram State Rural Livelihood Mission/
National Rural Livelihood Mission (MSRLM/NRLM), National Urban Livelihood Mission (NULM) and North East Rural Livelihood Project (NERLP). Earlier SHGs were formed under Swarnjayanti Gram Swarojgar Yojana (SGSY) throughout Mizoram. Formation of SHGs under SGSY was ended in 2010. Now since 2011-12 SHGs are being formed under National Rural Livelihood Mission (NRLM) only in two districts of Mizoram-Serchhip and Kolasib.

Pig is one of the most important livestock species reared in the north-eastern states of India. The region had 38-lakh pigs which was about $28 \%$ of the country's pig population (DES 2010). Mizoram is challenged for cultivation due to its steep slopes and hilly terrains. The practice of traditional subsistence cultivation (Jhum) still prevails. It is customary for the Mizo to rear one or two pigs as a source of subsidiary income. Consequently, pig rearing has become one of the important SHG activities of Mizo people. However, very negligible 
studies have been conducted on the SHGs in Mizoram. Keeping this in view, the present study was undertaken in the district of Serchhip and Kolasib where the National Rural Livelihood Mission (NRLM) had been forming SHGs around piggery since 2012. The objective was to study the socio-economic profile of SHGs and their members.

\section{Materials and Methods}

The study was conducted in two districts of Mizoram, namely, Serchhip and Kolasib. Serchhip is located at $23.3^{\circ} \mathrm{N} 92.83^{\circ} \mathrm{E}$ between the Mat and Tuikum rivers. According to census (2011), the district had a population of 64,875 of which male and female were 32,824 and 32,051 , respectively with a density of $46 \mathrm{~km}^{-2}$ with an area of about $1,421 \mathrm{~km}^{2}$. The district had two development blocks, namely, Serchhip and East Lungdar and had the highest literacy in India. Kolasib district is bound on the north and north-west by Hailakandi district (Assam), on the west by Mamit district, on the south-east by Aizawl district and on the north-east by Cachar district (Assam). According to census (2011), the district had a population of 83,054 of which male and female were 42,916 and 41,037 , respectively with a density of $61 \mathrm{~km}^{-2}$ and an area of $1,382.51 \mathrm{~km}^{2}$. The district had two development blocks, namely, Bilkhawthlir and Thingdawl and had 93.5\% literacy. Serchhip and Kolasib were selected purposively as these were the only two districts in Mizoram under which the National Rural Livelihood Mission (NRLM) have been taking initiative for formation and monitoring of SHGs. From each block of the two districts SHGs engaged in pig rearing activity for at least two years were shortlisted. Among the shortlisted SHGs five were randomly selected from each block. Thus, a total of 20 SHGs were selected and from each of the 20 SHGs five members were randomly selected on lottery basis to have a sample size of 100 for the study.

\section{Results and Discussion}

\subsection{Profile of SHG members}

\subsubsection{Age}

The SHGs members' age groups were found to have a wide range with lower and upper age limit 21 and 70 years, respectively. Following the age categorisation by census report (1981), Government of India, it was found that $26 \%$ of the respondents fell under the young age group, while majority $(41 \%)$ of the respondents fell under middle age group (35-50 years) and the remaining $33 \%$ were above 50 years of age which were classified as old age group (Table 1).

\begin{tabular}{lcc}
\hline \multicolumn{3}{l}{ Table 1: Age of the respondents } \\
\hline Age & Category & Percentage \\
\hline Up to 34 years & Young & 26 \\
35-50 years & Middle & 41 \\
Above 50 years & Old & 33 \\
\hline
\end{tabular}

Similar results were found by Vinayagamoorthy (2005) where large portion of the women-SHG members in Tamil Nadu belonged to the age group of 40-50 years (36\%) and 30-40 years $(32 \%)$. Finding was also similar with the report given by Das (2004) where majority of SHG members $(71.32 \%)$ were in the middle age group of 30-43 years while Sajesh (2006) recorded that majority of the SHG respondents under Kudumbashree (56\%) belonged to young age group $(<35$ years). Savitha and Rajasekhar (2014) also found that women members above 50 years of age were only $13.33 \%$ and majority of the respondents were of 31-40 years. This might be due to the fact that pig rearing needed little attention and could be taken up as subsidiary occupation where the elder members of the family could easily take up the task, leaving the younger family members for other works such as agricultural activities.

\subsubsection{Education}

Mizoram having $91.58 \%$ of literacy rate (2011 census) it is not surprising that there were no illiterate among the respondents in the present study. High school educated comprised of $48 \%$, middle school and primary educated comprised both of $17 \%$, and the respondents who had education up to higher secondary and graduate level comprised of 15 and $3 \%$, respectively (Table 2).

\begin{tabular}{llcc}
\hline \multicolumn{4}{l}{ Table 2: Education of the respondents } \\
\hline $\begin{array}{l}\text { S1. } \\
\text { No. }\end{array}$ & $\begin{array}{l}\text { Educational } \\
\text { qualification }\end{array}$ & $\begin{array}{c}\text { Percentage of } \\
\text { respondents }\end{array}$ & Score \\
\hline 1. & Illiterate & 0 & 0 \\
2. & Primary & 17 & 17 \\
3. & Middle & 17 & 34 \\
4. & High school & 48 & 144 \\
5. & Higher secondary & 15 & 60 \\
6. & Graduate & 3 & 15 \\
\hline
\end{tabular}

Results of the present study are in consonance with the Sajesh (2006) that majority of the SHG respondents under Kudumbashree were high school educated followed by primary school level constituting $35 \%$ and $33 \%$ of the respondents, respectively. This was not a surprising finding as the state holds a whooping percentage of 91.58 according to 2011 census.

\subsubsection{Occupation}

Majority $(76 \%)$ of the respondents practiced piggery as subsidiary occupation and only $24 \%$ had piggery as their main occupation. Of 100 respondents, 24 reared pigs, 42 were agriculturists, 24 were engaged in handloom and 10 were in petty trade as their main source of livelihood (Table 3).

Results were in agreement with the findings of Sasikala et al. (2011) who found that pig farmers maintained piggery as 


\begin{tabular}{lc}
\hline Table 3: Occupation of the respondents \\
\hline Main occupation & Percentage \\
\hline Agriculture & 42 \\
Piggery & 24 \\
Handloom & 24 \\
Petty trade & 10 \\
\hline
\end{tabular}

subsidiary occupation.

\subsubsection{Family size}

The respondents belonged to varying family members and types. Of 100 respondents, 25 belonged to joint family whereas the rest (75\%) belonged to nuclear type. According to the categorisation of Devi (2000), it can further be classified (Table 4).

\begin{tabular}{lcc}
\hline Table 4: Size of the respondents' family & \\
\hline Category & Members & Percentage \\
\hline Small & Up to 5 & 45 \\
Medium & $6-8$ & 50 \\
Large & Above 8 & 5 \\
Petty trade & 10 & \\
\hline
\end{tabular}

The finding is in conformity with Srivastava et al. (1996); Sharma et al. (2007). On the other hand, Divekar and Saiyed (2009) found that majority of the farmer belonged to joint family in Gujarat. Having joint or nuclear family depended on the tradition and culture of the societies on one hand and the growing necessities on the other hand.

\subsubsection{Income}

It was found that only $8 \%$ of the respondents had an income lower than the state specific below poverty line for Mizoram (2011-12), which was ₹ 63,960, another 34\% had income between the poverty line and the state per capita expenditure while the remaining 58\% had an income more than ₹ 83,066 (Table 5).

\begin{tabular}{lcc}
\hline \multicolumn{3}{l}{ Table 5: Annual income of the respondents } \\
\hline Category & Income & Percentage \\
\hline Low & Below ₹ 63960 & 8 \\
Medium & ₹ 63960 to ₹ 83066 & 34 \\
High & Above 83066 & 58 \\
\hline
\end{tabular}

Lalnunpuii (2012) also observed that all the pig farmers of Aizawl were from Above Poverty Line (APL) engaged in other activities. Pig rearing was not a primary source of income of the farmers and did not pay much effort to the pig farming.

This finding is in contrast with the findings of Savitha and Rajasekhar (2014) where majority of the respondents had a very low income of not more than ₹ 5,000. This might be the result of the continual rise in the price of piglet and pork in the state where both these components were in high demand creating stable market security and viable enterprise, further popularity of pork in relation to place also differed.

\subsubsection{Land holding}

Majority of the respondents (54\%) were marginal farmers with not more than 2.5 acres of land, followed by small farmers having farm area ranging from 2.6 to 5 acres comprising up to $27 \%$ of the respondents, and $7 \%$ were medium land holders whose farm area ranged from 5.1 to 7 acres. There were no respondents having a farm area larger than 10 acres, while there were $12 \%$ landless farmers. Kumar et al. (2004) and Sasikala et al. (2011) also reported that most of the farmers had marginal land holding with an area up to 2.5 acres (Table 6).

\begin{tabular}{lcc}
\hline \multicolumn{3}{l}{ Table 6: Land holding of the respondents } \\
\hline Category & Land holding (acre) & Percentage \\
\hline Landless & No land & 12 \\
Marginal & Up to 2.5 (1 ha) & 54 \\
Small & $2.6-5(1-2$ ha) & 27 \\
Medium & $5.1-10(2-4$ ha $)$ & 7 \\
Large & More than 10 & 0 \\
& (4 ha and above) & \\
\hline
\end{tabular}

Results are similar to Rao (2009), that in Assam, little over $2 \%$ members were from landless category, $85 \%$ were marginal farmers. Sajesh (2006) reported that majority of the group members $(66 \%)$ under study were having only marginal land holding.

Singh (2006) also revealed that most of the members (70.83\%) had small size of land holding (less than 3 acres). Only $6.67 \%$ members were in the category of higher medium land holding (7-15 acres) followed by those who were in the category of large land holdings (above 15 acres). Kumar et al. (2004); Sasikala et al. (2011) also reported that most of the farmers had marginal land holding with an area up to 2.5 acres. It may be due to the scarcity of cultivable land challenged by the topography and lack of water.

\subsubsection{Experience in piggery}

More than half $(55 \%)$ of the respondents had pig farming experience of 10 years or above and $28 \%$ had an experience ranging from 5 to 9 years while $17 \%$ had 5 years or less pig farming experience. This finding agrees with the result of Sasikala et al. (2011); Mahanjana and Cronje (2000) who found that farmers had high level of farming experience (Table 7).

\subsubsection{Herd size}

Herd size of the respondents ranged from 1 to 10 adult pigs, with $23 \%$ rearing only fattener pig, $17 \%$ only sow for breeding, 


\begin{tabular}{lcc}
\hline \multicolumn{3}{l}{ Table 7: Respondents' experience in piggery } \\
\hline Category & Year & Score \\
\hline Low & Less than 5 & 17 \\
Medium & $5-9$ & 56 \\
High & More than 10 & 165 \\
\hline
\end{tabular}

$55 \%$ both sow and fatteners, and 5\% rearing boars. Of 100 respondents, 41 possessed herd size of 1-2 pigs, 52 possessed $3-5$ pigs and 7 possessed above 5 pigs. The average herd size was found to be 3.09 (Table 8).

\begin{tabular}{lcc}
\hline \multicolumn{3}{l}{ Table 8: Herd size of the respondents' farms } \\
\hline Herd size & Percentage & Score \\
\hline $1-2$ & 41 & 17 \\
$3-5$ & 52 & 56 \\
Above 5 & 7 & 165 \\
\hline
\end{tabular}

This finding is in line with the findings of Kumaresan et al. (2006) who found that most of the farmers maintained small herd size in their farms. Pigs are reared mainly for subsidiary income. Hence herd size may be small.

\subsection{Profile of $\mathrm{SHG}$}

\subsubsection{Age}

Majority of the respondents (75\%) belonged to 2-year old SHG and 25\% were 3-year old. Reddy and Reddy (2012) reported that the average age of sample SHGs in Andhra Pradesh was high with 7.50 years and low in Bihar with 3.21 years compared to all other sample states (West Bengal-6.51, Assam-6.26, Karnataka-5.43, Rajasthan-5.34, Maharashtra-4.71 and Gujarat-3.39). It showed that states like Andhra Pradesh, West Bengal, Assam, and Karnataka had taken up the formation of SHGs very long back, under various states and centrally sponsored program and with the financial support of international agencies, namely, United Nations Development Program (UNDP), International Fund for Agricultural Development (IFAD), World Bank, etc.

This difference in the age of SHG of Mizoram and other state was due to the fact that SHGs were recently initiated by the government agency such as NRLM, NULM and NeRLP since 2012 and also NGOs like CODNERC, Open Doors, World Vision, etc. in promoting piggery among the SHG members.

\subsubsection{Members and their type}

The sample consisted $80 \%$ SHGs run by NGOs and $20 \%$ SHGs run by the government agencies. SHGs were classified into three types according to the type of membership namely female-SHG, male-SHG and mixed-SHG. Of 100 respondents, 60 belonged to female-SHGs while 40 belonged to mixed-SHG where there were both male and female members. All mixed-
SHGs were formed under NGOs and not by the government (Table 9).

\begin{tabular}{lcc}
\hline Table 9: Type of membership of SHG & \\
\hline Type of membership & Percentage & Score \\
\hline All male group & 0 & 17 \\
Mixed & 40 & 56 \\
All female group & 60 & 165 \\
\hline
\end{tabular}

Members varied from 5 to 10 , where $35 \%$ of the respondents belonged to 5 -member SHGs, $20 \%$ belonged to 6 -member SHGs, $15 \%$ belonged to 7 -member SHGs, $20 \%$ belonged to 8 -member SHGs, and 5\% belonged to 9 and 10 -member SHGs. The membership of the groups are small in numbers mainly due to the tender age of the SHG initiative taking place in the areas and the other reason is piggery being a new trade activity among the members many potential members refused to take up piggery as group activity and instead opt for other trade like handloom, agriculture activities, floriculture, etc.

Results are not similar to that of Rahman (2011) that average size of the sample dairy-SHG was 12 . He observed that in majority of the cases $(70 \%)$ size of the group was $10-12$. Five male groups $(41.67 \%)$ were having 10 members per group as against three woman groups $(37.50 \%)$. It was seen that the numbers of group members ranged from 10 to 18. Rao (2009) reported that the average size of the group was 12 . Feroze (2009); Sinha (2006) in their respective studies observed that average size of the groups was 14 . This difference in the number of members in the present study and other studies may be due to the fact that the study area is hilly and the population density of the state was just 52 persons $\mathrm{km}^{-2}$ compared to the national 382. Such groups consisting of less than 10 members are recognized as Joint Liability Group (JLG).

\subsubsection{Group activities}

\subsubsection{Savings}

All the SHGs under study had bank linkage with Rural Bank at their nearest branch and maintained proper transaction records. They also practiced book keeping supervised and monitored by their mentor. Monthly savings per member varied between ₹ 40 and ₹ 100 in all the groups. Of 100 respondents, 60 had monthly savings of ₹ 100, 30 had ₹ 80, and 10 had monthly savings of 40 . These savings were utilized mainly for internal lending among the group members.

Devi and Rani (2014) also reported that SHG women were saving ₹ 100 month $^{-1}$. Majority $(66 \%)$ of the SHG women saved ₹ 50 month $^{-1}$ and negligible percentage were saving ₹ 30 month $^{-1}$.

\subsubsection{Internal lending}

Of 100 respondents, 20 received revolving fund in the form 
of cash while 80 received fund in the form of aids such as piglets, housing materials and feeds. $60 \%$ of the groups had annual internal lending frequency of $3,20 \%$ had frequency of $4,10 \%$ had frequency of 1 , and another $10 \%$ had an average of 4 lending member-1 year ${ }^{-1}$. The interest rate of the internal lending was $3 \%$ annum $^{-1}$ in $80 \%$ of SHGs while it was $2 \%$ annum $^{-1}$ in $20 \%$ of SHGs. There was a set of penalty which varied from group to group regarding non-repayment of microlending, which was drafted by the members through consensus.

Jerinabi (2006) found that out of 357 SHGs, 301 availed internal loans from their respective groups providing the potential for self-help and mutual groups. Money was lent at a very much lower rate of interest. Therefore the unethical money lending practices were diminished to meet the emergency needs of the members.

\subsubsection{Roup meeting}

Majority (80\%) of the groups had fortnightly meeting, an average of twice a month, whereas $20 \%$ of the groups had group meeting every week, i.e. 4 meetings a month. All the groups had meeting during evening, between $7 \mathrm{pm}$ and $9 \mathrm{pm}$, and was presided by their respective group president.

Rao (2009) reported that majority (73\%) of the members conducted monthly meeting, $14 \%$ weekly meeting and $12 \%$ had fortnightly meeting. Ojha (2001) suggested that there should be rotation of group leadership so that all members of the group get an opportunity to play managerial role.

\subsubsection{Election}

All the groups had president/chairman, secretary and treasurer which were elected through voting from among all the group members. The election took place once a year. The president and secretary of a group was automatically a member of Primary Level Federation or Village Organization within a village council.

\subsubsection{Training}

The SHG members were imparted training by their respective agencies and line departments through resource persons on topics mainly dealing with banking practices. Besides these topics, SHGs who were solely engaged in pig farming were given training on pig management practices including housing, feeding, breeding, sanitary measures, vaccination, de-worming, treatment to common ailments, and care of sow and piglets. North East Initiative Development Agency (NEIDA) played an important role in imparting training to the SHG members in both the districts studied. Of 100 respondents, 30 attended two training on the topic pig farming, 40 attended one training and another 30 had not attended training on pig farming.

Results were similar to that of Das (2004) that most of the SHG members (88.52\%) had attended training on 1-3 aspects.
Study conducted to know the usefulness of training among the women members of SHG in Cuddalore district of Tamil Nadu showed that the women did tremendous improvement in their activities when given training through NGOs. It was found that activity-based skill training was highly useful (Vengatesan and Govind, 2006). Likewise, SHGs of the present study were constantly monitored by their agency and given training upon the areas where they lagged behind. This was one of the reasons for their high adoption behavior.

\section{Conclusion}

Profile of SHGs and their members engaged in pig rearing in Mizoram was studied. SHGs can be promoted among young and old. Members were literate. Pig rearing as a SHG activity was compatible to the society. Members joined to form Joint Liability Group (JLG). There was a scope for the government agencies to involve in the formation of SHGs. There is a need to study the relationship between profile of SHGs and their members and the performance of SHGs.

\section{References}

Das, B.C., 2004. Performance of Self Help Groups (SHGs) in dairy farming: A comprehensive study of Karnal district. $\mathrm{Ph} \mathrm{D}$ Thesis, National Dairy Research Institute, Karnal, Haryana, India.

DES, 2010. Statistical handbook of Mizoram. Directorate of Economics and Statistics, Government of Mizoram, Aizawl.

Devi, B.J., Rani, D.U., 2014. Gender and technology adoption-A study of self-help group beneficiaries. International Journal of Advanced Information Science and Technology 26(26), 122-129.

Devi, U.K., 2000. Women's equality in India: A myth or reality. Discovery Publishing House, Ansari Road, Darya Ganj, New Delhi.

Divekar, B.S., Saiyed, L.H., 2009. Socio-economic and literacy status and milking practices followed in middle Gujarat by professional Gir cattle breeders. Indian Journal of Field Veterinarian 4(4), 50-54.

Feroze, S.M., 2009. Economic analysis of dairy Self Help Groups in western zone of Haryana. PhD Thesis, National Dairy Research Institute, Karnal, Haryana, India.

Jerinabi, U., 2006. 'Micro credit management by women's selfhelp groups'. Discovery Publishing House, New Delhi.

Kashid, K., Wankhade, P.P., Mankar, D.M., 2009. Empowerment status of rural women through Self Help Groups. Indian Journal of Extension Education 45(3\&4), 106-112.

Kumar, R., Pal, P.P., Prasad, K., Naskar, S., 2004. Livestock management practices by the small holders of northeastern region. Indian Journal of Animal Science 74(8), 
882-886.

Kumaresan, A., Pathak, K.A., Bujarbaruah, K.M., Das, A., 2006. Swine production in Mizoram. Research bulletin No. 50. Indian Council of Agricultural Research Complex for North-eastern Hilly Region, Umiam, Meghalaya, India.

Lalnunpuii, 2012. Pig rearing by above poverty line (APL) families in Mizoram. MVSc Thesis, Assam Agricultural University, Jorhat, Guwahati, Assam, India.

Ojha, R.K., 2001, Self help groups and rural employment. Yojana 41, 20-23.

Rahman, S., 2011. Sustainability of dairy-based self-help groups (SHGs) in Assam: An exploratory study in Kamrup district. PhD Thesis, National Dairy Research Institute, Karnal, Haryana, India.

Ramesh, J., 2007. Self-help groups revolution: What next? Economic political weekly $8^{\text {th }}$ September, 3621-3624.

Rao, G.B., 2009. Quality and sustainability of SHGs in Assam. National bank for agriculture \& rural developmentsponsored study by APMAS \& NABARD collaboration, Banjara hills, Hyderabad.

Reddy, A., 2008. Self-help groups in India: A catalyst for women economic empowerment and poverty eradication. In: Proceeding of $33^{\text {rd }}$ Global Conference of ICSW, 30 June-4 July, TOURS, France.

Reddy, K.R., Reddy, C.S., 2012. Self Help Groups in India: A study on quality and sustainability. Available from: http://www.microfinancegateway.org/library/self-helpgroups-india-study-quality-and-sustainability. Accessed on 1 January 2016.

Sajesh, V.K., 2006. Impact assessment of SHG for the empowerment of rural poor. MSc Thesis, Indian Agricultural Research Institute, Pusa, New Delhi, India.
Sajesh, V.K., Ramasundaram, P., Singh, P., 2011. Impact of self help groups on the empowerment of rural women: A case of Kudumbasree program in Kerala. Indian Journal of Extension Education 47(3\&4), 14-19.

Sasikala, V., Kumaravel, P., Mathialagan, P., Saravanan, M., 2011. Symbolic adoption of modern pig farming technologies by rural pig farmers through interactive multimedia module. Animal Science Reporter 5(3), 95-100.

Savitha, V., Rajasekhar, H., 2014. Evaluation of major problems faced by the members of self-help groups: A study of Mysore district. International Journal of Research in Applied, Natural and Social Sciences 2(6), 2347-4580.

Sharma, M.C., Pathodiya, O.P., Jingar, S.C., Gaur, M., 2007. A study on socio-economic status of goat rearers and adoption of management practices. Indian Journal of Small Ruminants 13(1), 75-83.

Singh, U., 2006. Multi-dimensional impact of women dairy cooperative societies on beneficiaries in Haryana. PhD Thesis, National Dairy Research Institute, Karnal, Haryana, India.

Srivastava, A., Dubey, V.K., Misra, S.K., 1996. Impact of mass media on women of Varanasi. Interaction 15(2), 80-100.

Vengatesan, D., Govind, S., 2006. A study on the usefulness of activity based skill training as perceived by women SHG members. Crop Research 3(3), 483-484.

Vinayagamoorthy, A., 2005. Women empowerment through self-help groups: A case study in the north Tamil Nadu. Available from: http:/www.flyhighonline.com/flyhigh/ flyhigh/contentlinks/vinaigamurthy2.htm. Accessed on 1 January 2016. 